\title{
HUBUNGAN SKOR AWAL GCS DENGAN OUTCOME PADA PASIEN CEDERA KEPALA
}

\author{
Ida Zuhroidah ${ }^{1)}$,Mukhammad Toha ${ }^{2)}$ Mokh. Sujarwadi ${ }^{3)}$, Nurul Huda ${ }^{4)}$ \\ 1,2,3,4 Program Studi D3 Keperawatan Fakultas Keperawatan, Universitas Jember Kampus Kota Pasuruan, Indonesia \\ email: ida.akper@unej.ac.id
}

\begin{abstract}
Abstrak
Cedera kepala adalah gangguan struktur dan fungsi otak yang diakibatkan oleh gaya mekanik dari luar tubuh, ada beberapa faktor prognosis yang berhubungan dengan outcome pasien cedera kepala meliputi jenis kelamin, usia, skor awal GCS, reflek pupil, gambaran CT scan, tanda vital dan hasil laboratorium. Penelitian ini bertujuan untuk menganalisis hubungan antara skor awal GCS dengan outcome pada pasien cedera kepala di Rumah Sakit X di Pasuruan. Penelitian ini menggunakan metode observasional analitik dengan pendekatan desain cross sectional. Pengukuran variabel independen berupa tingkat kesadaran (GCS) dan variebel dependen berupa nilai Trauma and Injury Severity Score (TRISS) dilakukan secara simultan pada satu saat dan dinilai hanya satu kali saja. Populasi yang digunakan adalah semua pasien cedera kepala di IGD Rumah Sakit X di Pasuruan. Besar sampel yang digunakan adalah 53 responden dengan teknik concecutive sampling. Data diuji menggunakan correlational Kendall Tau dengan level signifikan $\leq$ 0.005. Hasil uji menunjukkan adanya hubungan antara Skor Awal GCS dengan Outcome pada Pasien Cedera Kepala dengan nilai $p=0.00 \leq 0.05$,nilai korelasi 0.402 yang berarti terdapat hubungan sangat erat dan bersifat positif, setiap terjadi penurunan GCS maka nilai TRISS juga akan menurun. Hasil penelitian ini memperkuat indikasi tentang pentingnya penanganan yang tepat dan segera pada penderita yang mengalami penurunan GCS diawal kejadian trauma.
\end{abstract}

Kata kunci: penderita trauma, GCS, TRISS.

\begin{abstract}
Head injury is a structure and function brain disorder caused by mechanical forces from outside the body; there are several prognostic factors related to the outcome of head injury, including gender, age, initial GCS score, pupillary reflex, CT scan images, vital signs and laboratory results. This study aims to analyze the relationship between the initial GCS score and the outcome in head injury patients in X Hospital Pasuruan. This study used an analytic observational method with a cross-sectional design approach. Measurement of the independent variable in the form of level of consciousness (GCS) and the dependent variable in the form of the Trauma and Injury Severity Score (TRISS) were carried out simultaneously at one time and were assessed once. The population was all head injury patients at the emergency department of X Hospital Pasuruan. The sample was 53 respondents taking by consecutive sampling technique. The data were tested using Kendall Tau correlational with a significant level of $<0.005$. The test results showed a relationship between the GCS Initial Score and the Outcome in Head Injury Patients with a value of $p=0.00<0.05, a$ correlation value of 0.402 which means that there positive close relationship, every time there is a decrease in GCS, the TRISS value will also decrease. This study's results strengthen the indication of the importance of prompt and appropriate treatment in patients who experience a decrease in GCS at the beginning of trauma.
\end{abstract}

Keywords: trauma sufferers, GCS, TRISS.

\section{PENDAHULUAN}

Cedera kepala merupakan gangguan struktur dan fungsi otak yang diakibatkan oleh gaya mekanik dari luar tubuh (Fortunato, 1996). Data Badan Pusat
Statistik (BPS) menyebutkan bahwa jumlah kecelakaan lalu Intas mencapai 98,4\%. Jumlah kecelakaan lalu lintas dalam 10 tahun terakhir mengalami fluktuasi (BPS, 2015). Menurut Riset 
Kesehatan Dasar tahun 2018, tempat terjadinya cedera paling banyak di jalan raya, sebesar $44,7 \%$. Kecelakaan lalu lintas terjadi pada pengendara sepeda motor sebesar 72,4\% mengkibatkan cedera (Kementerian Kesehatan Republik Indonesia, 2018).

Penelitian di Rotterdam menunjukkan tingginya angka mortalitas pada kelompok pasien cedera kepala usia $\geq 65$ tahun, yaitu mencapai $72 \%$, walaupun jumlah pasien usia $\geq 65$ tahun lebih sedikit dibandingkan pasien usia 15-64 tahun (Grigorakos et $a l, 2017)$. Penelitian di Athena menunjukkan tingkat mortalitas pada pasien perempuan $(34,95 \%)$ lebih tinggi dibandingkan pasien laki-laki (24,83\%). Berdasarkan mekanisme cedera, penyebab terbanyak cedera adalah kecelakaan kendaraan bermotor dengan tingkat mortalitas paling tinggi yaitu sebesar 28,31\% (El-Menyar et al., 2018). Dampak kerugian ekonomi akibat cidera khususnya akibat kecelakaan lalu lintas Di Indonesia diperkirakan sebesar 2,9\% pendapatan domestik bruto (PDB). Terjadinya cedera di seluruh dunia akibat kecelakaan lalu lintas. Tahun 2020, kecelakaan lalu lintas diperkirakan menempati peringkat ke-3, sedangkan pada DALY menempati urutan ke-9. Di negara berkembang, kecelakaan lalu lintas menempati urutan ke-2. Penyebab utama kematian serta ketidakmampuan secara umum di Negara berkembang adalah cedera akibat kecelakaan lalu-lintas (Riyadina \& Suhardi, Permana, 2009). Menurut Yuniarti (2007) cedera kepala menduduki urutan tertinggi yaitu 25,5\%-54,9\%, diikuti dengan terjadinya cedera pada ekstremitas yaitu 17,63$42,20 \%$, dan cedera pada dada dan perut sekitar $11.8 \%$. WHO menempatkan cedera kepala sebagai penyebab utama kecacatan dan kematian pada individu dibawah usia 45 tahun (Lagarde, 2019).

Hasil jangka panjang secara psikologis didapatkan bahwa depresi pada pasien setelah mengalami cedera kepala mengakibatkan kualitas hidup serta fungsional, psikologi yang buruk (Haagsma et al., 2015). Menurut (Kulesza et al., 2015) ada beberapa faktor prognosis outcome pasien cedera kepala antara lain jenis kelamin, usia, skor awal GCS, reflek pupil, gambaran $C T$ scan, tanda vital dan hasil laboratorium. Menurut (Moya Zamzami et al., 2013) tentang angka kejadian dan outcome cedera otak di RS. Hasan Sadikin Bandung didapatkan hasil bahwa angka kejadian cedera kepala perempuan $(20,2 \%)$ lebih rendah dari laki-laki (79,8\%) dan kejadian tertinggi rentang usia 18-45 Tahun. Interval waktu kedatangan pasien cedera kepala di IGD sampai dimulainya operasi, $60 \%$ lebih dari 6 jam dan $40 \%$ memerlukan waktu operasi kurang dari 6 jam. 94,7\% outcome baik terjadi pada pasien dengan cedera kepala ringan, sedangkan 5,3\% outcome buruk pada pasien cedera kepala sedang

Kondisi emergency pada pasien cedera kepala tentunya membutuhkan pertolongan cepat dan tepat untuk hasil outcome yang lebih baik. Penanganan yang cepat dan tepat akan berdampak pada kondisi fisik pasien. Harapannya angka kematian dan kecacatan pasien dapat menurun. Efektivitas waktu penatalaksanaan pasien cedera kepala oleh petugas merupakan hal yang penting. Gangguan metabolisme otak, gangguan transport substrat ke jaringan otak dan penurunan aliran darah ke otak merupakan dampak yang terjadi apabila cedera kepala tidak segera ditangani sehingga mengakibatkan iskemik otak. Cedera otak sekunder dan iskemik otak dapat terjadi 6 jam setelah kejadian sehingga tindakan terapi definitif harus dilakukan kurang dari 6 jam setelah kejadian, dan merupakan golden period (Imen et al., 2015).

Pertolongan yang optimal tentunya akan mempengaruhi kondisi pasien secara fisik, dimana kondisi fisik pasien akan mempengaruhi outcome pada pasien. Penelitian ini, peneliti mengkaji hubungan GCS dengan outcome pasien cedera kepala. Menentukan outcome pada pasien cedera kepala memang sulit, sedangkan outcome yang akurat sangat penting.

Salah satu pengukuran outcome cedera kepala dapat dilakukan dengan menggunakan Trauma and Injury Severity Score (TRISS). Selama 20 tahun terakhir ini, TRISS sudah digunakan hampir di seluruh dunia sebagai prediksi dampak dari trauma, dan konsisten pada orang dewasa serta anak-anak (Salim C, 2015). TRISS merupakan skoring yang digunakan untuk menganalisis kemungkinan hidup (Ps) pasien trauma berdasarakan score RTS dan ISS yang diformulasikan dengan koefisien dan indeks usia. TRISS memiliki sensitivitas (kemampuan mendeteksi kematian) 95\%, spesifisitas (kemampuan mendeteksi kelangsungan hidup) 96\%, dan akurasi 95\% (Schluter, 2011).

Rumah Sakit $X$ di Pasuruan merupakan Rumah Sakit Rujukan di Wilayah Pasuruan. Angka kecelakaan di Pasuruan jumlahnya cukup tinggi, kondisi jalan raya yang padat arus lalu lintas dan merupakan jalan utama Surabaya Bali serta kondisi medan jalan yang rawan kecelakaan membuat agka kecelekaan semakin tinggi. Dari data yang diperoleh dari Satlantas Polres Pasuruan ada 868 kasus kecelakaan pada tahun 2018. Sedangkan tahun 2017 hanya 809 kasus. Mayoritas korban berusia produktif antara 16-30 tahun (Muhajir Arifin, 2019). Data yang didapatkan dari Rumah Sakit penderita cedera kepala berdasarkan data rekam medik secara spesifik tercatat 
bahwa penderita cedera kepala ringan dalam tiga tahun terakhir yaitu pada 2014 sebanyak 167 kasus, tahun 2015 sebanyak 182 kasus sedangkan 2016 sebanyak 188 kasus. Tujuan penelitian ini adalah untuk mempelajari hubungan GCS dengan outcome pasien cedera kepala di Rumah Sakit X di Pasuruan.

\section{METODE PENELITIAN}

Metode penelitian ini menggunakan penelitian kuantitatif. Jenis penelitian yang digunakan adalah penelitian observasional analitik dengan pendekatan desain cross sectional. Dalam penelitian ini peneliti melakukan pengukuran atau mengobservasi data variabel bebas (independen) dan variebel terkait (dependen) secara stimultan pada suatu saat dan dinilai hanya satu kali saja. Populasi dalam penelitian adalah semua pasien cedera kepala di IGD Rumah Sakit X di Pasuruan. Estimasi selama dua bulan jumlah populasi dalam penelitian ini adalah 120 pasien cedera kepala. Penentuan diagnosa cedera kepala berat dibuat oleh dokter jaga IGD pada saat pasien datang Sampel dalam penelitian ini ditetapkan berdasarkan teknik concecutive sampling dengan jumlah sampel 53 orang.

Peneliti melakukan pengukuran tentang outcome dengan mengunakan instrument TRISS. Selain lembar observasi, digunakan form RTS nilai RTS yang berisi variabel nilai GCS. Lembar penilaian TRISS untuk menilai outcome pasien cedera kepala berupa persentase (\%) kemungkinan hidup Pada penelitian ini, instrumen yang digunakan adalah lembar pedoman observasi (check list). Instrumen RTS dan TRISS tidak dilakukan uji validitas dan reliabilitas karena merupakan instrumen yang sudah baku. Instrumen RTS mempunyai nilai sensifitas $88 \%$, spesifitas 94\%, dan akurasi $92 \%$. Tingkat sensitivitas TRISS adalah 95\%, spesifisitas $96 \%$, serta dengan nilai akurasi 95\%. Analisis bivariat yang digunakan dalam penelitian ini adalah Kendall's Tau, kemudian dianalisis dengan menggunakan SPSS untuk mengetahui hasilnya. Penelitian ini telah dinyatakan laik etik oleh Tim Etik Penelitian Kesehatan dengan nomor 445.1/3302/424.202/2019.

\section{HASIL DAN PEMBAHASAN}

Lokasi penelitian ini adalah di IGD Rumah Sakit X di Pasuruan yang dilaksanakan selama dua bulan. Rumah Sakit X merupakan Rumah Sakit rujukan baik dari Rumah Sakit lain maupun klinik yang ada di wilayah Pasuruan dan sekitarnya. Berikut hasil penelitian yang meliputi data umum responden antara lain usia, jenis truma yang dialami, frekuensi pernafasan serta tekanan darah sistolik.
Tabel 1. Karakteristik Responden Berdasarkan Usia, Jenis Truma, Frekuensi Pernafasan, Tekanan Darah Sistolik.

\begin{tabular}{|c|c|c|c|}
\hline No & Karakteristik & $\mathbf{n}$ & $\%$ \\
\hline \multicolumn{4}{|c|}{1 Usia } \\
\hline & $<55$ tahun & 46 & 86.7 \\
\hline & $>55$ tahun & 7 & 13,3 \\
\hline \multirow[t]{3}{*}{2} & Jenis Trauma & & \\
\hline & Trauma Tajam & 13 & 24.5 \\
\hline & Trauma Tumpul & 40 & 75.5 \\
\hline \multirow[t]{5}{*}{3} & Frekuensi Pernafasan & & \\
\hline & $1-5 \mathrm{x} / \mathrm{mt}$ & 0 & 0 \\
\hline & $6-9 \mathrm{x} / \mathrm{mt}$ & 0 & 0 \\
\hline & $10-29 \mathrm{x} / \mathrm{mt}$ & 51 & 96.2 \\
\hline & $>29 \mathrm{x} / \mathrm{mt}$ & 2 & 3.8 \\
\hline \multirow[t]{5}{*}{4} & Tekanan Darah Sistolik & & \\
\hline & $1-49 \mathrm{mmHg}$ & 0 & 0 \\
\hline & $50-75 \mathrm{mmHg}$ & 0 & 0 \\
\hline & 76-89 mmHg & 0 & 0 \\
\hline & $>89 \mathrm{mmHg}$ & 53 & 100 \\
\hline
\end{tabular}

Berdasarkan tabel 1 menunjukkan responden yang paling banyak pada penelitian ini yaitu umur $<55$ tahun sebanyak 46 orang $(86,7 \%)$.

Tabel 2. Hasil pengukuran Revised Trauma Score (RTS), Injury Severity Score (ISS), Glasgow Coma Scale (GCS), Trauma and Injury Severity Score (TRISS)

\begin{tabular}{|c|c|c|c|}
\hline No & Karakteristik & $\mathrm{n}$ & $\%$ \\
\hline \multirow[t]{5}{*}{1} & RTS & & \\
\hline & Slight & 0 & 0 \\
\hline & Moderate & 15 & 28.3 \\
\hline & Severe & 29 & 54.7 \\
\hline & Serious & 9 & 16.9 \\
\hline \multirow[t]{5}{*}{2} & ISS & & \\
\hline & Minor & 3 & 5.6 \\
\hline & Moderate & 3 & 5.6 \\
\hline & Severe & 43 & 81.1 \\
\hline & Extremely Severe & 4 & 7.5 \\
\hline \multirow[t]{7}{*}{3} & GCS & & \\
\hline & Composmentis & 13 & 24.5 \\
\hline & Apatis & 5 & 9.4 \\
\hline & Delirium & 13 & 24.5 \\
\hline & Somnolen & 21 & 39.6 \\
\hline & Sopor & 1 & 1.8 \\
\hline & Coma & 0 & 0 \\
\hline \multirow[t]{7}{*}{4} & TRISS & & \\
\hline & $0-10 \%$ & 0 & 0 \\
\hline & $11-20 \%$ & 0 & 0 \\
\hline & $21-30 \%$ & 0 & 0 \\
\hline & $31-40 \%$ & 0 & 0 \\
\hline & $41-50 \%$ & 1 & 1.8 \\
\hline & $51-60 \%$ & 0 & 0 \\
\hline
\end{tabular}




\begin{tabular}{ccc}
\hline $61-70 \%$ & 1 & 1.8 \\
$71-80 \%$ & 1 & 1.8 \\
$81-90 \%$ & 3 & 5.6 \\
$91-100 \%$ & 47 & 88.7 \\
\hline
\end{tabular}

Tabel 3. Hasil Analisis uji Kendall's Tau hubungan antara skor awal Glasgow Coma Scale dengan Out come (TRISS) pasien cedera kepala

\begin{tabular}{cccc}
\hline & & $\begin{array}{c}\text { Score } \\
\text { GCS }\end{array}$ & $\begin{array}{c}\text { Score } \\
\text { TRISS }\end{array}$ \\
\hline \multirow{4}{*}{ Score GCS } & $\begin{array}{l}\text { Correlation } \\
\text { Coefficient }\end{array}$ & 1.000 & $.402^{* *}$ \\
& $\begin{array}{c}\text { Sig.(2-tailed) } \\
\mathrm{N}\end{array}$ &. & .000 \\
& $\mathrm{~N}$ & 53 \\
\hline
\end{tabular}

Berdasarkan hasil penelitian menunjukkan bahwa terdapat hubungan yang signifikan antara skor GCS saat masuk IGD dengan Trauma and Injury Severity Score penderita cedera kepala di IGD Rumah Sakit X di Pasuruan $(p=0,000)$. Hasil uji Kendall's juga menunjukkan adanya hubungan yang cukup kuat antara skor GCS saat masuk IGD dengan Trauma and Injury Severity Score penderita cedera kepala di IGD Rumah Sakit X di Pasuruan dengan nilai 0.402 . sedang sifat hubungan menunjukkan arah positif yang berati bahwa semakin rendah skor GCS maka semakin rendah prosentase kemungkinan hidup pasien cedera kepala.

Menurut (Tude Melo et al., 2010) di Perancis mortalitas pasien cedera kepala berat didapatkan hasil bahwa terdapat hubungan antara skor GCS $\leq 5$ dengan kematian pasien cedera kepala berat $(p<0,05)$. Hasil yang sama juga ditunjukkan oleh penelitian (Ristanto \& Zakaria, 2017) dimana ada hubungan yang bermakna antara skor GCS di awal masuk IGD dengan mortality pasien dalam 7 hari perawatan $(\mathrm{p}=0,000)$. Kesimpulan yang didapatkan adalah bahwa mortality pasien cedera kepala berhubungan dengan GCS. Pada pasien cedera kepala dengan GCS 8 memiliki prediksi mortality naik menjadi 40\%, sedangkan GCS 8-12 memiliki prediksi mortality yang meningkat menjadi $5 \%$, dan GCS 15 memiliki prediksi mortality sebesar $1 \%$, (Glance \& Borley, 2007). Dari hasil tersebut menunjukkan bahwa tingkat keberfungsian otak bisa diukur dengan menggunakan GCS. Otak sebagai pusat kontrol dari fungsi organ pada seluruh tubuh manusia, apabila mengalami kegagalan fungsi organ maka berdampak secara langsung pada kelangsungan hidup seseorang.
Semakin rendah skor GCS, maka tingkat kerusakan neurologis yang terjadi pada serebrum dan batang otak semakin berat (Ting et al., 2010).

Menurut Kung et al. (2011) pada pasien yang mengalami cedera kepala, GCS bisa sebagai alat yang digunakan untuk prognosis. Pendapat yang sama juga disampaikan oleh Brazinova et al. (2010) bahwa prognosis pasien cedera kepala dipengaruhi oleh skor GCS dan merupakan parameter penentu prognosis pasien cedera kepala. Menurut Maiti \& Bidinger (2018) GCS memiliki hubungan moderat terhadap status keluar pasien (IK 95\%; $\mathrm{p}=0,018 ; \mathrm{r}=0,361$ ). Korelasi antara GCS dan status keluar pasien merupakan korelasi positif, yaitu makin rendah nilai GCS, makin banyak status keluar meninggal. Hasil yang serupa juga ditujukkan oleh Kulesza et al. (2015) dimana pasien yang masuk dengan skor GCS yang rendah dikaitkan dengan hasil yang lebih buruk. GCS menunjukkan hubungan linear yang jelas dengan mortalitas.

Menurut Sastrodiningrat (2010) yang mengutip pendapat Jennet dkk, bahwa $82 \%$ pasien dengan skor skala koma glasgow 11 atau lebih, dalam waktu 24 jam setelah cedera mempunyai good outcome atau moderately disabled dan hanya $12 \%$ yang meninggal atau mempunyai severe disability. Secara progresif outcome akan menurun jika skor awal skala koma glasgow juga menurun. Diantara penderita-penderita dengan skor skala koma glasgow 3 atau 4 dalam waktu 24 jam pertama setelah mengalami cedera hanya $7 \%$ yang mempunyai good outcome atau moderate disability. Diantara penderita-penderita dengan skor skala koma glasgow 3 pada waktu masuk dirawat, $87 \%$ akan meninggal. Kehilangan kesadaran yang lama, dalam banyak hal tidak prediktif terhadap outcome yang buruk. Skor skala koma glasgow merupakan indikator-indikator dini yang paling penting dan dominan dalam memprediksi prognosa penderita cedera kepala berat.

Menurut American Association of Neurological Surgeons (2020) penentuan skor awal skala koma glasgow yang dapat dipercaya dan belum diberi pengobatan apapun atau sebelum tindakan intubasi mempunyai nilai yang sangat penting; 20\% dari penderita dengan skor awal (skala koma glasgow) yang buruk akan survive dan 8-10\% akan mendapat penyembuhan fungsional (functional survival).

Adapun dari hasi penelitian didapatkan hasil bahwa semakin baik skor GCS maka outcome pasien juga akan semakin baik. Dalam hal ini 
berarti perawat dan petugas kesehatan yang lain harus berkoordinasi untuk segera melakukan penanganan terhadap pasien dengan skor GCS yang lebih rendah.

\section{KESIMPULAN DAN SARAN}

Terdapat hubungan yang sangat kuat antara skor awal GCS dengan outcome (TRISS) pasien cedera kepala di IGD Rumah Sakit X di Pasuruan. Semakin tinggi skor awal GCS maka semakin tinggi pula nilai Trauma and Injury Severity Score atau kemungkinan hidup pasien cedera kepala di IGD Rumah Sakit X di Pasuruan, demikian pula sebaliknya jika nilai skor awal GCS rendah. Trauma and Injury Severity Score (TRISS) bisa digunakan perawat dalam melakukan pengkajian pasien cedera kepala di IGD sehingga probability of survival pada pasien segera diketahui serta dapat menentukan langkah yang cepat dan tepat dalam penanganan pasien cedera kepala

\section{REFERENSI}

American Association of Neurological Surgeons. (2020). Management and Prognosis of Severe Traumatic Brain Injury. Brain Trauma Foundation.

BPS. (2015). Statistik transportasi darat 2014. Badan Pusat Statsistik Indonesia.

Brazinova, A., Mauritz, W., Leitgeb, J., Wilbacher, I., Majdan, M., Janciak, I., \& Rusnak, M. (2010). Outcomes of patients with severe traumatic brain injury who have glasgow coma scale scores of 3 or 4 and are over 65 years old. Journal of Neurotrauma, 27(9), 15491555. https://doi.org/10.1089/neu.2010.1315

El-Menyar, A., Consunji, R., Abdelrahman, H., Latifi, R., Wahlen, B. M., \& Al-Thani, H. (2018). Predictors and Time-Based Hospital Mortality in Patients with Isolated and Polytrauma Brain Injuries. World Journal of Surgery, 42(5), 1346-1357. https://doi.org/10.1007/s00268-017-4310-2

Fortunato, N. (1996). Pathophysiology: The Biologic Basis for Disease in Adults and Children. In AORN Journal (Vol. 63, Issue 1). Mosby Elsevier. https://doi.org/10.1016/s00012092(06)63479-0

Glance, P. A., \& Borley, N. R. (2007). At Glance Ilmu Bedah. Erlangga.
Haagsma, J. A., Scholten, A. C., Andriessen, T. M. J. C., Vos, P. E., Van Beeck, E. F., \& Polinder, S. (2015). Impact of Depression and PostTraumatic Stress Disorder on Functional Outcome and Health-Related Quality of Life of Patients with Mild Traumatic Brain Injury. Journal of Neurotrauma, 32(11), 853-862. https://doi.org/10.1089/neu.2013.3283

Imen, R. B., Olfa, C., Kamilia, C., Meriam, B., Hichem, K., Adel, C., Mabrouk, B., \& Noureddine, R. (2015). Factors predicting early outcome in patients admitted at emergency department with severe head trauma. Journal of Acute Disease, 4(1), 68-72. https://doi.org/10.1016/s2221-6189(14)60087-1

Kementerian Kesehatan Republik Indonesia. (2018). Riset Kesehatan Dasar 2018.

Kulesza, B., Nogalski, A., Kulesza, T., \& Prystupa, A. (2015). Prognostic factors in traumatic brain injury and their association with outcome. Journal of Pre-Clinical and Clinical Research, 9(2), 163-166. https://doi.org/10.5604/18982395.1186499

Kung, W. M., Tsai, S. H., Chiu, W. T., Hung, K. S., Wang, S. P., Lin, J. W., \& Lin, M. S. (2011). Correlation between Glasgow coma score components and survival in patients with traumatic brain injury. Injury, 42(9), 940-944. https://doi.org/10.1016/j.injury.2010.09.019

Lagarde, E. (2019). Road traffic injuries. Encyclopedia of Environmental Health. https://doi.org/10.1016/B978-0-444-639516.00623-9

Maiti, \& Bidinger. (2018). Perbandingan Glasgow Coma Scale dan Gambaran Midline-Shift CTScan Kepala sebagai Prediktor Mortalitas Pasien Cedera. Albert Tito Sonny Saragih, 53(9), 1689-1699.

Moya Zamzami, N., Fuadi, I., \& Nawawi, A. M. (2013). Angka Kejadian dan Outcome Cedera Otak di RS. Hasan Sadikin Bandung Tahun 2008-2010. Jurnal Neuroanestesi Indonesia, 2(2), 89-94. https://doi.org/10.24244/jni.vol2i2.167

Muhajir Arifin. (2019). Kecelakaan di Pasuruan Meningkat, 176 Orang Meninggal di 2018. DetikNews. https://news.detik.com/beritajawa-timur/d-4367045/kecelakaan-dipasuruan-meningkat-176-orang-meninggal-di2018 
Ristanto, R., \& Zakaria, A. (2017). Analisis Akurasi Glasgow Coma Scale (GCS) Dalam Memprediksi Mortality Pasien Cedera Kepala. Prosiding Seminar Nasional, 95-99.

Riyadina, W., \& Suhardi, Permana, M. (2009). Pola dan Determinan Sosiodemografi Cedera Akibat Kecelakaan Lalu Lintas di Indonesia. Majalah Kedokteran Indonesia, 59(10), 464-472.

Salim C. (2015). Sistem Penilaian Trauma. CDK, 42(9), 702-709. http://www.cdkjournal.com/ index.php/CDK/article/view/973/698

Sastrodiningrat, A. G. (2010). Memahami FaktorFaktor yang Mempengaruhi Prognosa Cedera Kepala Berat. Majalah Kedokteran Nusantara.

Schluter, P. J. (2011). The Trauma and Injury Severity Score (TRISS) revised. Injury. https://doi.org/10.1016/j.injury.2010.08.040
Ting, H. W., Chen, M. S., Hsieh, Y. C., \& Chan, C. L. (2010). Good Mortality Prediction by Glasgow Coma Scale for Neurosurgical Patients. Journal of the Chinese Medical Association, 73(3), 139-143. https://doi.org/10.1016/S1726-4901(10)70028-9

Tude Melo, J. R., Rocco, F. Di, Blanot, S., Oliveira-Filho, J., Roujeau, T., Sainte-Rose, C., Duracher, C., Vecchione, A., Meyer, P., \& Zerah, M. (2010). Mortality in children with severe head trauma: Predictive factors and proposal for a new predictive scale. Neurosurgery, 67(6), 1542-1547. https://doi.org/10.1227/NEU.0b013e3181fa7 049

Yuniarti. (2007). Epidemologi Trauma Secara Global. Journal, 1-13. 